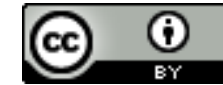

Esta obra está sob o direito de Licença Creative Commons Atribuição 4.0 Internacional.

\title{
ANÁLISE DOS SISTEMAS DE ESGOTAMENTO SANITÁRIO ÚNICO E SEPARADOR
}

Flávio Júnior Bezerra ${ }^{1}$

Gabryell Henrique Amancio da Silva ${ }^{2}$

Igor Bruno do Nascimento Santos ${ }^{3}$

Ivis Kally Pereira Patriota ${ }^{4}$

Letícia Karen Pereira Martins ${ }^{5}$

Eduardo Cabral da Silva ${ }^{6}$

\section{RESUMO}

Esgotamento sanitário é o conjunto de medidas que visam modificar e prevenir problemas relacionados as condições do meio ambiente. Basicamente está relacionado ao abastecimento de água, o manejo de água pluvial, a coleta e tratamento de esgoto. Em épocas chuvosas existe grande probabilidade de sobrecarregamento das redes, ocasionando transtorno à população e danos orçamentários aos municípios. Quais seriam as melhores estruturas do esgotamento sanitário para evitar problemas ocasionados por enchentes? O presente trabalho tem como objetivo apresentar os pontos positivos e negativos de uma rede de esgotamento sanitário com separação das águas pluviais e efluentes por meio de discussões. $\mathrm{O}$ artigo trata-se de uma revisão bibliográfica do tipo sistemática integrativa, onde arquivos foram pesquisados no Periódicos CAPES, utilizando os descritores: efluentes, esgotamento sanitário, sistema e estação de tratamento, empregando escolha dos critérios de inclusão e exclusão. Identificando estudos pré-selecionados e selecionados através da leitura dos agentes indexadores das publicações. Por meio das discussões e os resultados obtidos, a conclusão enquanto pode alcançar é que o esgotamento sanitário separador é o ideal no sistema de esgotamento sanitário.

Descritores: Efluentes. Pluviais. Rede. Tratamento. Ambiente.

\footnotetext{
1 flavio.junior@grupomoura.com

2 henriquegabryell08@hotmail.com

3 igor.ns996@gmail.com

4. ivis.patriota@gmail.com

5. leticia_karen2011@hotmail.com

${ }^{6}$ eduardo.csilva@professores.unifavip.edu.br
} 


\section{INTRODUÇÃO}

Em termos de rede de esgoto, água, tratamento de esgoto e outras coisas mais, uma série de medidas que são tomadas para melhorar as condições sanitárias mínimas dos moradores: o saneamento básico é direito de todo indivíduo.

Esgotamento Sanitário está relacionado à higiene e manutenção da saúde pública ou pessoal. Antes dos esgotos serem programados para coletar, conduzir e retirar todos os resíduos gerados e dar-lhes o tratamento adequado, tinham como objetivo apenas de evitar enchentes urbanas.

\section{METODOLOGIA}

Esta é uma revisão bibliográfica do tipo sistemática integrativa, que segue as seguintes etapas (ver Quadro 1): $1^{\text {a }}$ ) A definição do tema, a seleção das questões norteadoras e a seleção das estratégias de pesquisa, descritores e base de dados mais eficazes no levantamento das publicações; $2^{\mathrm{a}}$ ) Escolha dos critérios de inclusão e exclusão; $3^{\text {a }}$ ) Identificação dos estudos préselecionados e selecionados através da leitura dos agentes indexadores das publicações, como resumo, palavras-chave e título, bem como organização dos estudos pré-selecionados e identificação dos estudos selecionados; 4a ) Além da análise
Em períodos de elevados índices pluviométricos, os sistemas de coleta e escoamento dos esgotos sanitários acabam sobrecarregados, favorecendo a ocorrência de vazamentos e a formação de depósitos nas ruas. Então, quais seriam as melhores estruturas para fazer o escoamento do esgotamento sanitário para que não houvesse problemas de enchentes?

Este artigo tem como objetivo trazer uma discussão sobre os pontos favoráveis e desfavoráveis de uma rede que separe água pluvial de efluentes.

das informações, da formação de bibliotecas individuais e da avaliação rigorosa dos estudos selecionados, os estudos selecionados também são classificados e a matriz composta é elaborada e utilizada; $5^{\mathrm{a}}$ ) análise, interpretação e discussão dos resultados; $6^{\mathbf{a}}$ ) Apresentação da revisão em formato de artigo, o qual contemple sugestões para pesquisas futuras. (BOTELHO; CUNHA; MACEDO, 2011; SCHMOELLER et al., 2011). Os Quadros a seguir detalha as etapas da revisão abrangente do sistema e os resultados obtidos. 
Quadro 1 - Detalhamento das etapas da Revisão Sistemática Integrativa.

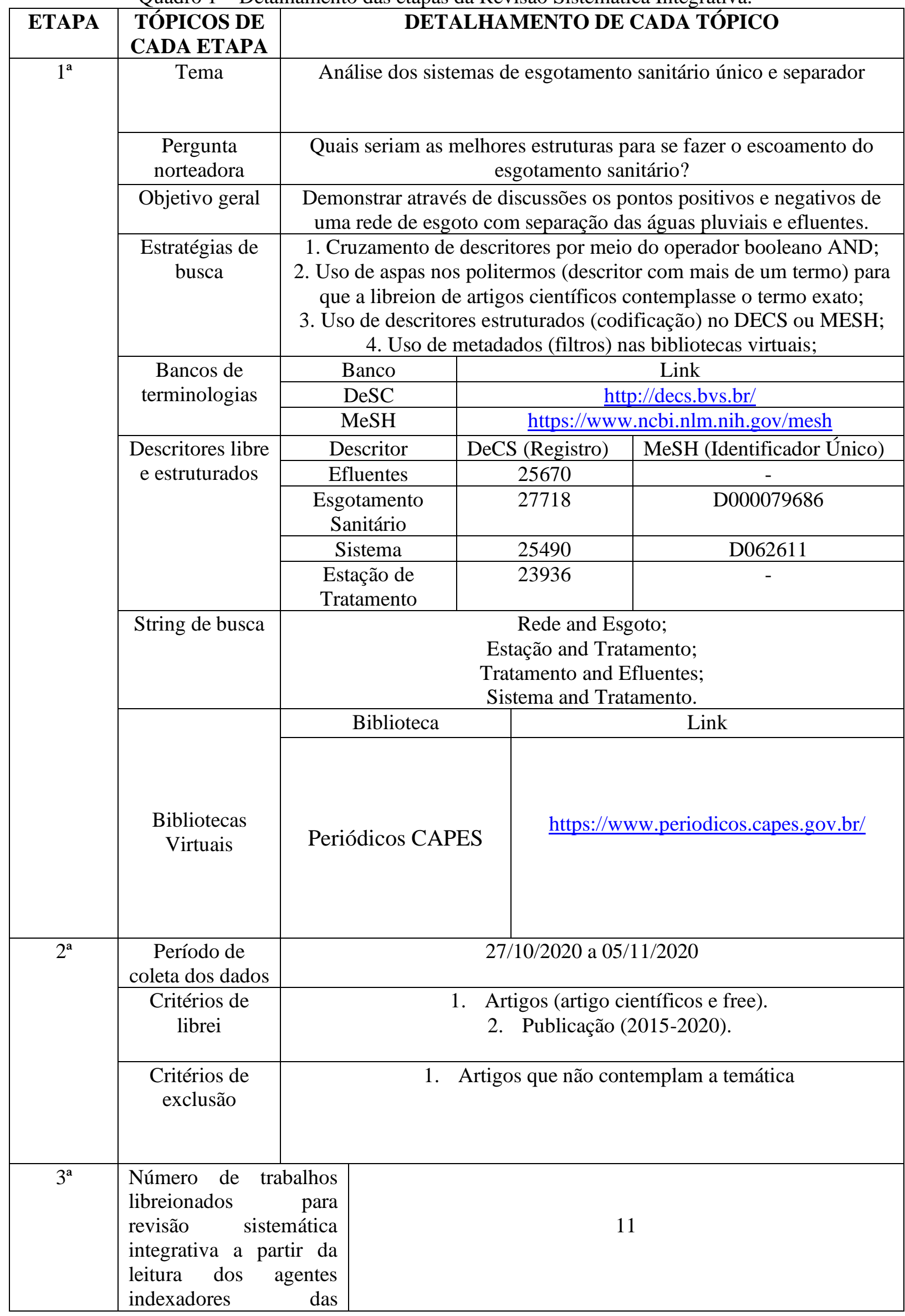




\begin{tabular}{|c|c|c|}
\hline & $\begin{array}{l}\text { publicações (tema, } \\
\text { descrição, ementa). }\end{array}$ & \\
\hline $4^{\mathrm{a}}$ & 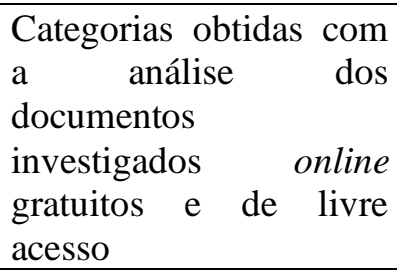 & 3 \\
\hline $5^{a}$ & $\begin{array}{l}\text { Análise, interpretação e } \\
\text { discussão dos resultados }\end{array}$ & Ver em "Resultados e Discussão" \\
\hline $6^{\mathrm{a}}$ & $\begin{array}{l}\text { Apresentação da revisão } \\
\text { em formato de artigo, o } \\
\text { qual contemple } \\
\text { propostas para estudos } \\
\text { futuros }\end{array}$ & Este Artigo completo \\
\hline
\end{tabular}

Fonte: elaborada pelos autores.

\section{RESULTADOS}

Quadro 2 - Corresponde ao total de documentos disponíveis na Plataforma obtidos por string

\begin{tabular}{|c|c|c|c|c|}
\hline String de busca & $\begin{array}{c}\text { Bases de } \\
\text { dados }\end{array}$ & $\begin{array}{c}\text { Total de } \\
\text { publicações } \\
\text { sem o filtro }\end{array}$ & $\begin{array}{l}\text { Publicações } \\
\text { disponíveis após } \\
\text { aplicar os filtros }\end{array}$ & $\begin{array}{c}\text { Publicações } \\
\text { aproveitadas na } \\
\text { Revisão Sistemática } \\
\text { Integrativa }\end{array}$ \\
\hline \multirow{4}{*}{$\begin{array}{l}\text { Rede and Esgoto } \\
\text { Estação and } \\
\text { Tratamento } \\
\text { Tratamento and } \\
\text { Efluentes } \\
\text { Sistema and } \\
\text { Tratamento }\end{array}$} & $\begin{array}{c}\text { Periódico } \\
\text { CAPES }\end{array}$ & 1.046 & 378 & 2 \\
\hline & $\begin{array}{c}\text { Periódico } \\
\text { CAPES }\end{array}$ & 2.525 & 850 & 6 \\
\hline & $\begin{array}{c}\text { Periódico } \\
\text { CAPES }\end{array}$ & 1.759 & 756 & 1 \\
\hline & $\begin{array}{c}\text { Periódico } \\
\text { CAPES }\end{array}$ & 23.073 & 8.941 & 2 \\
\hline
\end{tabular}

Quadro 3- Descrição dos documentos (artigos) de acordo com os critérios de inclusão.

\begin{tabular}{|c|c|c|c|c|c|}
\hline $\mathbf{N}^{\mathbf{0}}$ & Autor(a) & Tema & Link da publicação & $\begin{array}{c}\text { Data de } \\
\text { publicação }\end{array}$ & Conclusão \\
\hline 1 & $\begin{array}{l}\text { Graziela } \\
\text { Pinto de } \\
\text { Freitas; } \\
\text { Rosinete } \\
\text { Batista } \\
\text { dos } \\
\text { Santos } \\
\text { Ribeiro; } \\
\text { Kardelan } \\
\text { Arteiro da } \\
\text { Silva; } \\
\text { Ingrid } \\
\text { Lélis }\end{array}$ & $\begin{array}{l}\text { Sistema de } \\
\text { tratamento } \\
\text { de efluentes } \\
\text { para o } \\
\text { campus da } \\
\text { Universida } \\
\text { de Federal } \\
\text { de Campina } \\
\text { Grande na } \\
\text { cidade de } \\
\text { Pombal }\end{array}$ & $\begin{array}{l}\text { https://www.gvaa.com.br/re } \\
\text { vista/index.php/RVADS/art } \\
\text { icle/view/4525 }\end{array}$ & $01 / 04 / 2016$ & $\begin{array}{l}\text { O atual sistema de } \\
\text { tratamento do Campus } \\
\text { apresenta falhas, } \\
\text { podendo causar } \\
\text { reações adversas tanto } \\
\text { ao meio ambiente } \\
\text { como a população } \\
\text { acadêmica. } \\
\text { Com relação às } \\
\text { medidas mitigadoras } \\
\text { indicadas no estudo, } \\
\text { destacam-se: expansão } \\
\text { das fossas sépticas }\end{array}$ \\
\hline
\end{tabular}




\begin{tabular}{|c|c|c|c|c|c|}
\hline & $\begin{array}{l}\text { Ricarte } \\
\text { Cavalcant } \\
\text { e. }\end{array}$ & & & & $\begin{array}{l}\text { recuperação e } \\
\text { recomposição } \\
\text { paisagística das áreas } \\
\text { já afetadas e medidas } \\
\text { de controle ambiental } \\
\text { decorrentes do } \\
\text { armazenamento, } \\
\text { transporte e disposição } \\
\text { final do lodo. } \\
\text { O processo biológico } \\
\text { por reator UASB } \\
\text { apresenta-se como } \\
\text { alternativa viável de } \\
\text { acordo com as } \\
\text { características do local } \\
\text { a ser implantado, } \\
\text { apresentando uma } \\
\text { significativa remoção } \\
\text { de DBO/DQO, } \\
\text { apresentando baixos } \\
\text { requisitos de área e } \\
\text { baixo tempo de } \\
\text { detenção hidráulica. } \\
\text { Seu desempenho } \\
\text { justifica-se pelo fato } \\
\text { de que parte da } \\
\text { matéria orgânica é } \\
\text { mineralizada para gás } \\
\text { e água e, outra parte é } \\
\text { convertida em } \\
\text { biomassa bacteriana, } \\
\text { que pode ser } \\
\text { reutilizada no próprio } \\
\text { sistema, o que } \\
\text { representa uma grande } \\
\text { economia. }\end{array}$ \\
\hline 2 & $\begin{array}{l}\text { Randal } \\
\text { Magnani; } \\
\text { Eduardo } \\
\text { da Silva } \\
\text { Lima. }\end{array}$ & $\begin{array}{l}\text { O impacto } \\
\text { da nova } \\
\text { estação de } \\
\text { tratamento } \\
\text { de efluentes } \\
\text { do } \\
\text { município } \\
\text { de } \\
\text { Resende-RJ } \\
\text { para o } \\
\text { fortalecime } \\
\text { nto do } \\
\text { conceito de } \\
\text { cidade } \\
\text { sustentável }\end{array}$ & $\begin{array}{l}\text { https://indexlaw.org/index. } \\
\text { php/revistards/article/view/ } \\
4112\end{array}$ & $21 / 07 / 2018$ & $\begin{array}{l}\text { O presente trabalho } \\
\text { teve por finalidade } \\
\text { analisar o impacto da } \\
\text { nova estação de } \\
\text { tratamento de } \\
\text { efluentes da cidade de } \\
\text { Resende-RJ para o } \\
\text { fortalecimento do } \\
\text { conceito de cidade } \\
\text { sustentável e para a } \\
\text { preservação do meio } \\
\text { ambiente, bem de uso } \\
\text { comum de todos. } \\
\text { Como se sabe, o } \\
\text { saneamento básico na } \\
\text { sua vertente coleta e } \\
\text { tratamento de } \\
\text { efluentes é somente }\end{array}$ \\
\hline
\end{tabular}




\begin{tabular}{|c|c|c|c|c|c|}
\hline & & & & & $\begin{array}{l}\text { uma parcela do que } \\
\text { seria realmente uma } \\
\text { cidade sustentável, } \\
\text { que envolve também a } \\
\text { qualidade do ar, a } \\
\text { coleta e reciclagem do } \\
\text { lixo urbano, utilização } \\
\text { de fontes renováveis } \\
\text { de energia e até } \\
\text { mesmo a manutenção } \\
\text { de áreas verdes, dentre } \\
\text { outras. } \\
\text { A fim de se atingir o } \\
\text { objetivo proposto, } \\
\text { partiu-se da } \\
\text { necessidade de } \\
\text { apresentar os } \\
\text { conceitos de } \\
\text { consciência ecológica } \\
\text { e pegada ecológica, } \\
\text { este último } \\
\text { internacionalmente } \\
\text { reconhecido como } \\
\text { uma das formas de } \\
\text { medir a utilização, } \\
\text { pelo homem, dos } \\
\text { recursos naturais, } \\
\text { portanto, relacionado } \\
\text { com o } \\
\text { desenvolvimento } \\
\text { sustentável. [...] }\end{array}$ \\
\hline 3 & $\begin{array}{l}\text { Vanessa } \\
\text { Silva } \\
\text { Chaves; } \\
\text { Erwin } \\
\text { Henrique } \\
\text { Meneses } \\
\text { Schneider } \\
\text {; Arthur } \\
\text { Silva } \\
\text { Passos } \\
\text { Lima; } \\
\text { Luciana } \\
\text { Coêlho } \\
\text { Mendonç } \\
\text { a. }\end{array}$ & $\begin{array}{l}\text { Desempenh } \\
\text { o das } \\
\text { estações de } \\
\text { tratamento } \\
\text { do esgoto } \\
\text { de Aracaju }\end{array}$ & $\begin{array}{l}\text { http://revistadae.com.br/arti } \\
\text { gos/artigo_edicao_209_n_1 } \\
\text { 699.pdf }\end{array}$ & $01 / 01 / 2018$ & $\begin{array}{l}\text { Diante dos resultados } \\
\text { obtidos, verifica-se } \\
\text { que a } \\
\text { ERQ Oeste e a ETE } \\
\text { Visconde de Maracaju } \\
\text { cumpriram } \\
\text { integralmente todas as } \\
\text { condições para os } \\
\text { parâmetros analisados, } \\
\text { no que diz respeito às } \\
\text { exigências } \\
\text { da legislação } \\
\text { ambiental vigente, a } \\
\text { Resolução } \\
\text { Conama 430. } \\
\text { As demais estações } \\
\text { descumpriram a } \\
\text { legislação } \\
\text { em algum momento, } \\
\text { com destaque para a } \\
\text { ETE }\end{array}$ \\
\hline
\end{tabular}




\begin{tabular}{|c|c|c|c|c|c|}
\hline & & & & & $\begin{array}{l}\text { Orlando Dantas, que } \\
\text { apresentou o pior } \\
\text { resultado, } \\
\text { ultrapassando o limite } \\
\text { tolerado de DBO em } \\
\text { duas } \\
\text { coletas e de sólidos } \\
\text { sedimentáveis em uma } \\
\text { coleta. } \\
\text { O baixo desempenho } \\
\text { dessa estação deve-se, } \\
\text { dentre } \\
\text { outros motivos, à } \\
\text { qualidade do esgoto } \\
\text { bruto } \\
\text { recebido, inclusive, } \\
\text { DBO superior aos } \\
\text { valores típicos, } \\
\text { fator que a torna mais } \\
\text { suscetível ao } \\
\text { descumprimento } \\
\text { da legislação. [...] }\end{array}$ \\
\hline 4 & $\begin{array}{l}\text { Claudinei } \\
\text { Fonseca } \\
\text { Souza; } \\
\text { Reinaldo } \\
\text { Gaspar } \\
\text { Bastos; } \\
\text { Marcus } \\
\text { Paulo de } \\
\text { Moraes } \\
\text { Gomes; } \\
\text { André } \\
\text { Arashiro } \\
\text { Pulschen. }\end{array}$ & $\begin{array}{l}\text { Eficiência } \\
\text { de estação } \\
\text { de } \\
\text { tratamento } \\
\text { de esgoto } \\
\text { doméstico } \\
\text { visando } \\
\text { reuso } \\
\text { agrícola }\end{array}$ & $\begin{array}{l}\text { http://www.scielo.br/scielo. } \\
\text { php?script=sci_arttext\&pid } \\
=\text { S1980- } \\
\text { 993X2015000300587 }\end{array}$ & $01 / 09 / 2015$ & $\begin{array}{l}\text { Nas condições } \\
\text { experimentais pôde-se } \\
\text { concluir que a ETE } \\
\text { apresenta ser eficiente } \\
\text { na capacidade de } \\
\text { depuração de matéria } \\
\text { orgânica e nutrientes. } \\
\text { O efluente final é } \\
\text { composto por } \\
\text { elementos de } \\
\text { importância agrícola } \\
\text { tais como nitrogênio, } \\
\text { fósforo, cálcio e } \\
\text { potássio e, juntamente } \\
\text { com a carga de } \\
\text { matéria orgânica e } \\
\text { sais, enquadra-se, nas } \\
\text { determinações da } \\
\text { NBR 13.969/1997 } \\
\text { (ABNT, 1997) para } \\
\text { reutilização na } \\
\text { agricultura. } \\
\text { Apesar da eficácia da } \\
\text { ETE na remoção de } \\
\text { matéria orgânica e da } \\
\text { capacidade de } \\
\text { remoção de coliformes } \\
\text { totais e E. coli, } \\
\text { observa-se a } \\
\text { necessidade de } \\
\text { tratamento terciário } \\
\text { para remoção de }\end{array}$ \\
\hline
\end{tabular}




\begin{tabular}{|c|c|c|c|c|c|}
\hline & & & & & $\begin{array}{l}\text { patógenos, porém sem } \\
\text { descartar } \\
\text { monitoramentos } \\
\text { periódicos da } \\
\text { salinidade do solo. }\end{array}$ \\
\hline 5 & $\begin{array}{l}\text { Fabrício } \\
\text { Oliveira } \\
\text { Dias; } \\
\text { Jémison } \\
\text { Mattos } \\
\text { dos } \\
\text { Santos; } \\
\text { Sampaio } \\
\text { de Jesus. }\end{array}$ & $\begin{array}{l}\text { Tratamento } \\
\text { de esgoto } \\
\text { doméstico a } \\
\text { partir di } \\
\text { sistema } \\
\text { Leito de } \\
\text { Raízes: } \\
\text { experiência } \\
\text { em uma } \\
\text { pequena } \\
\text { comunidad } \\
\text { e rural do } \\
\text { semiárido } \\
\text { brasileiro. }\end{array}$ & $\begin{array}{l}\text { https://periodicos2.uesb.br/i } \\
\text { ndex.php/geo/article/view/4 } \\
392\end{array}$ & $01 / 12 / 2018$ & $\begin{array}{l}\text { Confirma-se que o } \\
\text { manejo inadequado } \\
\text { das águas servidas, o } \\
\text { descarte de efluentes } \\
\text { nos solos e a ausência } \\
\text { do saneamento básico } \\
\text { na EFACI constituem- } \\
\text { se graves problemas } \\
\text { locais, que ainda não } \\
\text { foram solucionados. } \\
\text { Uma vez que a } \\
\text { inexistência de } \\
\text { estações de tratamento } \\
\text { de efluentes } \\
\text { domésticos contribui } \\
\text { decisivamente para a } \\
\text { poluição e a possível } \\
\text { contaminação dos } \\
\text { corpos hídricos } \\
\text { superficiais e } \\
\text { subterrâneos, dos } \\
\text { solos e a propagação } \\
\text { de patologias } \\
\text { veiculadas } \\
\text { hidricamente. } \\
\text { Dentre as alternativas } \\
\text { para equacionar as } \\
\text { questões supracitadas, } \\
\text { sinaliza-se } \\
\text { destacadamente o uso } \\
\text { e a aplicação da } \\
\text { técnica de tratamento } \\
\text { de efluentes } \\
\text { domésticos por meio } \\
\text { do sistema de leito de } \\
\text { raízes/leitos } \\
\text { cultivados, devido ao } \\
\text { baixo custo de } \\
\text { implantação, o } \\
\text { reduzido consumo de } \\
\text { energia e manutenção, } \\
\text { bem como por ser um } \\
\text { sistema relativamente } \\
\text { simples de construir. } \\
\text { Além disso, a } \\
\text { promoção de } \\
\text { melhorias das } \\
\text { condicões sanitárias e }\end{array}$ \\
\hline
\end{tabular}




\begin{tabular}{|c|c|c|c|c|c|}
\hline & & & & & $\begin{array}{l}\text { estéticas na paisagem. } \\
{[\ldots]}\end{array}$ \\
\hline 6 & $\begin{array}{l}\text { Gustavo } \\
\text { Stolzenbe } \\
\text { rg } \\
\text { Colares; } \\
\text { Fagner } \\
\text { Pereira da } \\
\text { Silva; } \\
\text { Gleison } \\
\text { de Souza } \\
\text { Celente; } \\
\text { Julia } \\
\text { Fernanda } \\
\text { Radkte; } \\
\text { Ennio } \\
\text { Leandro } \\
\text { Machado. }\end{array}$ & $\begin{array}{l}\text { Sistema } \\
\text { integrado } \\
\text { de } \\
\text { tratamento } \\
\text { de efluentes } \\
\text { sanitários } \\
\text { com } \\
\text { reatores } \\
\text { anaeróbicos } \\
\text { sequenciais } \\
\text { em } \\
\text { Batelada e } \\
\text { Wetlands } \\
\text { construídos } \\
\text { de fluxos } \\
\text { alternados }\end{array}$ & $\begin{array}{l}\text { https://online.unisc.br/seer/i } \\
\text { ndex.php/tecnologica/articl } \\
\text { e/view/10496 }\end{array}$ & $01 / 01 / 2018$ & $\begin{array}{l}\text { Os resultados obtidos } \\
\text { com o sistema } \\
\text { integrado WCFFH+ } \\
\text { WCFFA+ WCFV } \\
\text { foram satisfatórios, } \\
\text { principalmente em } \\
\text { termos de remoção N- } \\
\text { NH3, fósforo solúvel e } \\
\text { turbidez. } \\
\text { Considerando a } \\
\text { simplicidade de } \\
\text { projeto, construção e } \\
\text { manutenção, bem } \\
\text { como potencial baixo } \\
\text { custo, o sistema } \\
\text { apresenta um grande } \\
\text { potencial para } \\
\text { aplicação em zonas } \\
\text { rurais e/ou de baixa } \\
\text { densidade } \\
\text { populacional. É } \\
\text { importante destacar } \\
\text { também que as } \\
\text { diferenças encontradas } \\
\text { nos resultados das } \\
\text { análises } \\
\text { (principalmente no } \\
\text { efluente bruto) entre } \\
\text { os meses de fevereiro } \\
\text { e de março ocorreram } \\
\text { devido ao início do } \\
\text { semestre letivo, } \\
\text { momento no qual } \\
\text { ocorreu um aumento } \\
\text { significativo de } \\
\text { pessoas na } \\
\text { universidade. Espera- } \\
\text { se que nos meses } \\
\text { posteriores aos } \\
\text { resultados obtidos, até } \\
\text { o presente momento, o } \\
\text { sistema possa } \\
\text { apresentar-se mais } \\
\text { eficiente no } \\
\text { tratamento dos } \\
\text { efluentes } \\
\text { (principalmente em } \\
\text { relação a remoção de } \\
\text { COT), devido ao } \\
\text { desenvolvimento do } \\
\text { sistema radicular das } \\
\text { macrófitas, uma vez }\end{array}$ \\
\hline
\end{tabular}




\begin{tabular}{|c|c|c|c|c|c|}
\hline & & & & & $\begin{array}{l}\text { que as mudas } \\
\text { utilizadas eram } \\
\text { relativamente novas e } \\
\text { possuíam raízes pouco } \\
\text { desenvolvidas. [...] }\end{array}$ \\
\hline 7 & $\begin{array}{l}\text { Rodrigo } \\
\text { Braga } \\
\text { Moruzzi. }\end{array}$ & $\begin{array}{l}\text { Estimativa } \\
\text { do } \\
\text { lançamento } \\
\text { de água } \\
\text { pluvial no } \\
\text { sistema de } \\
\text { coleta e } \\
\text { transporte } \\
\text { de esgoto } \\
\text { sanitário } \\
\text { por meio de } \\
\text { práticas de } \\
\text { aproveitam } \\
\text { ento em } \\
\text { residências } \\
\text { unifamiliar } \\
\text { es }\end{array}$ & $\begin{array}{l}\text { http://www.scielo.br/scielo. } \\
\text { php?script=sci_serial\&pid= } \\
1413- \\
4152 \& \operatorname{lng}=\text { en\&nrm=iso }\end{array}$ & $01 / 03 / 2016$ & $\begin{array}{l}\text { Os resultados } \\
\text { apontaram que a } \\
\text { eficiência do sistema } \\
\text { de aproveitamento } \\
\text { de água pluvial } \\
\text { (SAAP) variou de } 24 \text { a } \\
87 \% \text { para áreas de } \\
\text { cobertura de } \\
\text { telhado de } 4 \text { a } 300 \\
\text { m2.hab.-1 e volumes } \\
\text { de reservatórios de } 0,5 \\
\text { a } 3,0 \text { m3.hab.-1, } \\
\text { os quais } \\
\text { corresponderam a } \\
\text { volumes ofertados } \\
\text { médios de água } \\
\text { pluvial da ordem } \\
\text { de } 8 \text { a } 370 \text { L/hab.dia } \\
\text { para a demanda média } \\
\text { otimizada, para } 0,5 \\
\text { m3.hab.-1. } \\
\text { O lançamento de água } \\
\text { pluvial na rede } \\
\text { coletora de } \\
\text { esgotamento sanitário } \\
\text { apresenta valores } \\
\text { menores que } 30 \% \text { para } \\
\text { áreas específicas de } \\
\text { cobertura de } 4 \text { a } \\
\text { 25 m2.hab.-1, com } \\
\text { reservação de } 0,5 \\
\text { m3.hab.-1 para todas } \\
\text { as faixas de consumo } \\
\text { per capita simuladas } \\
\text { (120,150, 180 e } 250 \\
\text { L.hab.-1.dia-1), } \\
\text { indicando que a } \\
\text { descargas } \\
\text { em bacias sanitárias } \\
\text { não são plenamente } \\
\text { atendidas nessas } \\
\text { condições. } \\
\text { Para } 3 \text { m3 de } \\
\text { reservatório.hab.-1, } \\
\text { valores da ordem de } \\
\text { 15 m2 de } \\
\text { cobertura.hab.-1 são } \\
\text { suficientes para }\end{array}$ \\
\hline
\end{tabular}




\begin{tabular}{|c|c|c|c|c|c|}
\hline & & & & & $\begin{array}{l}\text { atender plenamente a } \\
\text { bacia } \\
\text { sanitária, com base no } \\
\text { consumo de } 120 \\
\text { L.hab-1.dia-1. Para } \\
150 \text { L.hab-1. } \\
\text { dia-1, a descarga em } \\
\text { bacia foi plenamente } \\
\text { atendida a partir de } \\
\text { áreas } \\
\text { específicas de } \\
\text { cobertura de } 20 \text { e } 35 \\
\text { m2/hab., para } 3 \text { e } 0,5 \\
\text { m3 de reservatório. } \\
\text { hab.-1, } \\
\text { respectivamente. [...] }\end{array}$ \\
\hline 8 & $\begin{array}{l}\text { Murilo } \\
\text { Bertolino; } \\
\text { Jonas } \\
\text { Heitor } \\
\text { Kondages } \\
\text { ki; Regina } \\
\text { Weinschu } \\
\text { tz. }\end{array}$ & $\begin{array}{l}\text { Água de } \\
\text { chuva } \\
\text { domiciliar } \\
\text { no esgoto } \\
\text { separador } \\
\text { absoluto }\end{array}$ & $\begin{array}{l}\text { http://revistadae.com.br/arti } \\
\text { gos/artigo_edicao_213_n_1 } \\
\text { 741.pdf }\end{array}$ & $01 / 10 / 2018$ & $\begin{array}{l}\text { Os dados } \\
\text { georreferenciados das } \\
\text { vistorias ambientais } \\
\text { (SANEPAR, 2012) } \\
\text { para afluxo de água de } \\
\text { chuva } \\
\text { predial na rede de } \\
\text { esgoto foram } \\
\text { adequados para } \\
\text { criar um mapa de } \\
\text { densidade de } \\
\text { irregularidades } \\
\text { para a bacia com } \\
\text { maior histórico de } \\
\text { acréscimo de } \\
\text { vazão na estação de } \\
\text { tratamento durante } \\
\text { período } \\
\text { de chuva, a bacia do } \\
\text { Rio Belém e para } \\
\text { identificar as } \\
\text { áreas com maiores } \\
\text { densidade de } \\
\text { irregularidades. [...] }\end{array}$ \\
\hline 9 & $\begin{array}{l}\text { Gisele } \\
\text { Silva de } \\
\text { Souza; } \\
\text { Samanta } \\
\text { Tolentino } \\
\text { Cecconell } \\
\text { o; Luana } \\
\text { Nunes } \\
\text { Centeno. }\end{array}$ & $\begin{array}{l}\text { Redes } \\
\text { ociosas: um } \\
\text { estudo de } \\
\text { caso sobre } \\
\text { a percepção } \\
\text { da } \\
\text { população } \\
\text { do bairro } \\
\text { Laranja } \\
\text { quanto à } \\
\text { obrigatorie } \\
\text { dade da } \\
\text { ligação dos } \\
\text { ramais }\end{array}$ & $\begin{array}{l}\text { http://periodicos.ifsul.edu.b } \\
\text { r/index.php/thema/article/vi } \\
\text { ew/882 }\end{array}$ & $01 / 10 / 2018$ & $\begin{array}{l}\text { Pode-se concluir que } \\
\text { dentre os entrevistados } \\
\text { houve uma } \\
\text { preocupação e } \\
\text { interesse em se } \\
\text { adequar à legislação } \\
\text { municipal para } \\
\text { promover a qualidade } \\
\text { de vida da população e } \\
\text { consequentemente da } \\
\text { salubridade ambiental } \\
\text { da Laguna dos Patos. } \\
\text { Provavelmente este } \\
\text { interesse em realizar a }\end{array}$ \\
\hline
\end{tabular}




\begin{tabular}{|c|c|c|c|c|c|}
\hline & & $\begin{array}{l}\text { prediais à } \\
\text { rede } \\
\text { pública } \\
\text { coletora de } \\
\text { esgotos }\end{array}$ & & & $\begin{array}{l}\text { ligação predial dos } \\
\text { esgotos sanitários à } \\
\text { rede pública se dê em } \\
\text { virtude do alto padrão } \\
\text { de vida da população } \\
\text { entrevistada que } \\
\text { atrelada à alta } \\
\text { escolaridade, permite } \\
\text { que } 72 \% \text { dos } \\
\text { entrevistados já } \\
\text { estejam com seu } \\
\text { sistema de } \\
\text { esgotamento } \\
\text { conectado à rede. Com } \\
\text { relação à ociosidade } \\
\text { da rede coletora, este } \\
\text { estudo pôde } \\
\text { demonstrar que das } \\
\text { residências } \\
\text { entrevistadas, apenas } \\
85 \text { haviam realizado a } \\
\text { ligação à rede, } \\
\text { representando } 18,4 \% \\
\text { do total das } \\
\text { residências ligadas. } \\
\text { Deste modo, neste } \\
\text { estudo concluiu-se que } \\
\text { a rede coletora de } \\
\text { esgotos no bairro } \\
\text { Laranjal apresenta } \\
81,6 \% \text { de ociosidade. } \\
\text { O fator econômico é o } \\
\text { grande empecilho para } \\
\text { que haja a ligação dos } \\
\text { ramais prediais de } \\
\text { esgoto sanitário à rede } \\
\text { pública de coleta de } \\
\text { esgotos, visando } \\
\text { diminuir a ociosidade } \\
\text { da rede. } \\
\end{array}$ \\
\hline 10 & $\begin{array}{l}\text { Gustavo } \\
\text { Paiva } \\
\text { Weyne } \\
\text { Rodrigues } \\
\text {; } \\
\text { Guilherm } \\
\text { e Marques } \\
\text { Farias; } \\
\text { Luís } \\
\text { Henrique } \\
\text { Magalhãe } \\
\text { s Costa; } \\
\text { Marco } \\
\text { Aurélio }\end{array}$ & $\begin{array}{l}\text { Otimização } \\
\text { do traçado } \\
\text { de redes } \\
\text { coletoras de } \\
\text { esgoto } \\
\text { sanitário } \\
\text { via } \\
\text { algoritmo } \\
\text { genético }\end{array}$ & $\begin{array}{l}\text { http://revistadae.com.br/arti } \\
\text { gos/artigo_edicao_222_n_1 } \\
\text { 841.pdf }\end{array}$ & $01 / 03 / 2020$ & $\begin{array}{l}\text { Diante da importância } \\
\text { de uma rede de esgoto } \\
\text { sanitário para a } \\
\text { promoção da saúde } \\
\text { pública e do } \\
\text { elevado custo de } \\
\text { execução, faz-se cada } \\
\text { vez mais } \\
\text { necessária a aplicação } \\
\text { de métodos de } \\
\text { otimização } \\
\text { visando a diminuir os } \\
\text { custos envolvidos, de }\end{array}$ \\
\hline
\end{tabular}




\begin{tabular}{|c|c|c|c|c|c|}
\hline & $\begin{array}{l}\text { Holanda } \\
\text { de Castro. }\end{array}$ & & & & $\begin{array}{l}\text { forma a buscar o } \\
\text { máximo } \\
\text { aproveitamento do } \\
\text { capital } \\
\text { investido por órgãos } \\
\text { governamentais. } \\
\text { O resultado obtido } \\
\text { com o modelo em } \\
\text { questão } \\
\text { foi satisfatório. Além } \\
\text { disso, vale destacar a } \\
\text { utilização } \\
\text { do sentido do } \\
\text { escoamento como } \\
\text { variável } \\
\text { de decisão, pois a } \\
\text { topografia tem } \\
\text { impacto direto } \\
\text { e bastante expressivo } \\
\text { no valor do custo final } \\
\text { de } \\
\text { uma rede de esgoto. } \\
\text { [...] }\end{array}$ \\
\hline 11 & $\begin{array}{l}\text { Thiago } \\
\text { Zschornac } \\
\mathrm{k} \text {; } \\
\text { Therezinh } \\
\text { a Maria } \\
\text { Novais de } \\
\text { Oliveira. }\end{array}$ & $\begin{array}{l}\text { Avaliação } \\
\text { do impacto } \\
\text { da } \\
\text { implantaçã } \\
\text { o do } \\
\text { sistema de } \\
\text { esgotament } \\
\text { o sanitário } \\
\text { na } \\
\text { qualidade } \\
\text { da água da } \\
\text { Bacia } \\
\text { Hidrográfic } \\
\text { a do Rio } \\
\text { Cachoeira, } \\
\text { em } \\
\text { Joinville, } \\
\text { Santa } \\
\text { Catarina }\end{array}$ & $\begin{array}{l}\text { http://revistadae.com.br/arti } \\
\text { gos/artigo_edicao_212_n_1 } \\
\text { 727.pdf }\end{array}$ & 01/09/2018 & $\begin{array}{l}\text { A compreensão das } \\
\text { relações entre } \\
\text { saneamento, } \\
\text { saúde e meio ambiente } \\
\text { constitui uma das } \\
\text { etapas } \\
\text { mais importantes no } \\
\text { planejamento de } \\
\text { qualquer } \\
\text { política pública. Todo } \\
\text { investimento requer } \\
\text { um retorno, } \\
\text { seja ele mensurável ou } \\
\text { não. No caso do } \\
\text { investimento } \\
\text { em saneamento, } \\
\text { especificamente no } \\
\text { componente de } \\
\text { esgotamento sanitário, } \\
\text { o maior } \\
\text { retorno reside na } \\
\text { melhoria das } \\
\text { condições ambientais, } \\
\text { sociais e de saúde } \\
\text { pública. } \\
\text { A partir deste estudo } \\
\text { realizado na Bacia } \\
\text { Hidrográfica } \\
\text { do Rio Cachoeira, em } \\
\text { Joinville, foi possível }\end{array}$ \\
\hline
\end{tabular}




\begin{tabular}{|l|l|l|}
\hline & $\mid \begin{array}{l}\mid \\
\end{array}$ & $\begin{array}{l}\text { constatar que as obras } \\
\text { de expansão do } \\
\text { sistema de } \\
\text { esgotamento sanitário } \\
\text { realizadas no } \\
\text { município } \\
\text { vêm apresentando } \\
\text { impacto positivo na } \\
\text { qualidade } \\
\text { da água dos rios que a } \\
\text { compõem. Fato que } \\
\text { ajuda a } \\
\text { confirmar que os } \\
\text { investimentos em } \\
\text { esgotamento } \\
\text { sanitário representam } \\
\text { a principal solução } \\
\text { para a } \\
\text { despoluição de } \\
\text { qualquer rio urbano. } \\
\text { [...] }\end{array}$ \\
\hline
\end{tabular}

Fonte: elaborada pelos autores.

O corpo textual foi analisado por meio da frequência de palavras, que originou a nuvem de palavras (Figura 1) criada na Plataforma online WordArt. Esta ferramenta agrupa e organiza graficamente as palavras-chave evidenciando-as as mais frequentes.

Figura 1 - Nuvem de palavras

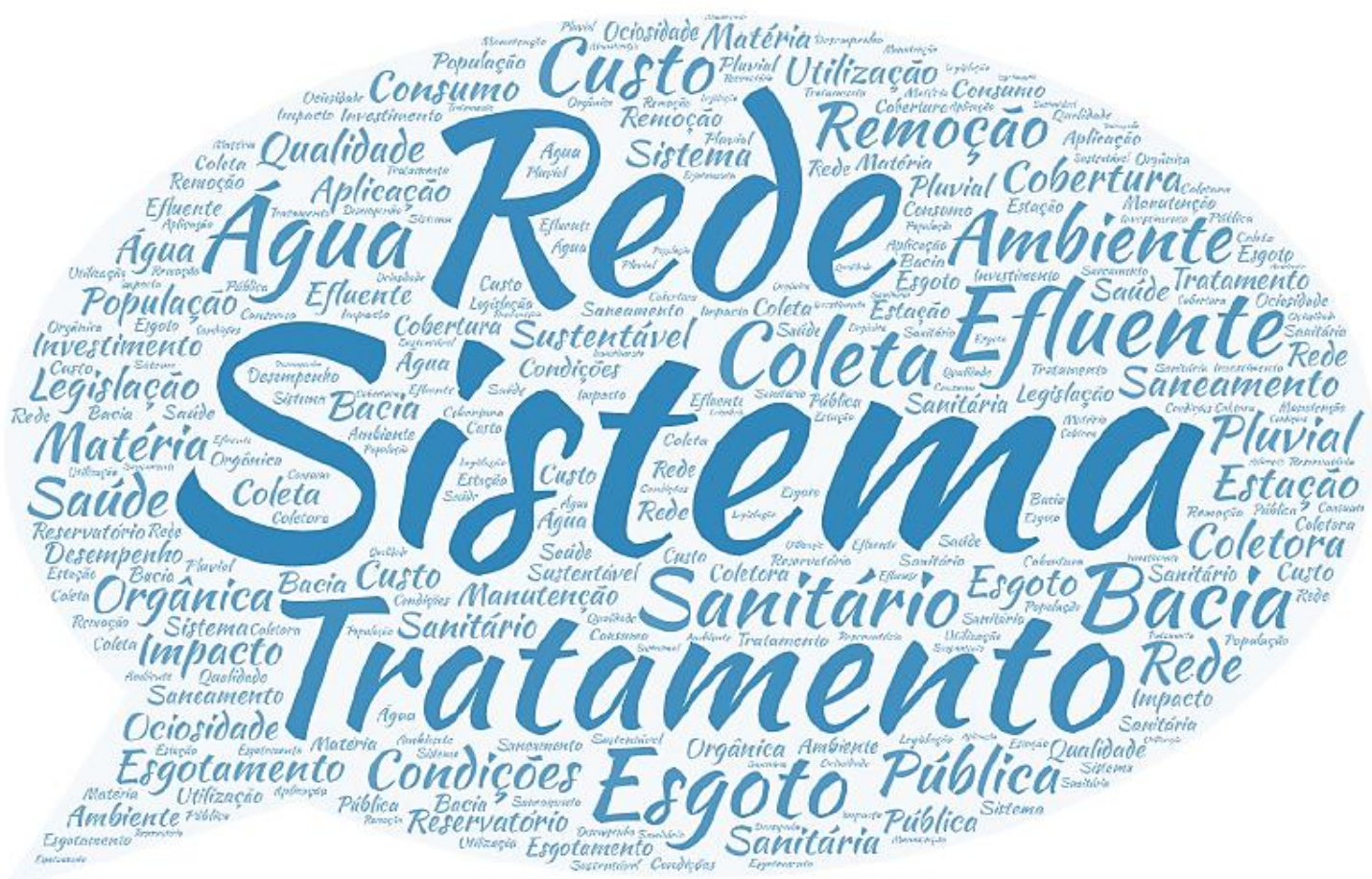

Fonte: elaborada pelos autores. 
Por meio da Figura 1, foi possível observar que as palavras em evidência na nuvem pertencem as categorias desenvolvidas a partir da análise de conteúdo de Bardin. Todas as categorias derivam da sua frequência (Tabela 1), que diz respeito ao seu quadro referencial. Em consonância ao objetivo deste trabalho, optou-se por descrever as palavras que apresentaram frequência total no texto e, a partir de seus sentidos nos campos textuais, tinham maior relevância para as representações sociais sobre os tipos de redes hidráulicas e as suas funcionalidades em questão do escoamento e tratamento de esgoto, como apresentado na Figura1.

Tabela 1. Frequência das palavras presentes nos textos publicados na Plataforma Periódico CAPES

\begin{tabular}{|c|c|c|}
\hline PALAVRAS & FREQUÊNCIA & CATEGORIAS \\
\hline Sistema & 11 & 14 \\
\hline Rede & 11 & 4 \\
\hline Tratamento & 8 & 0 \\
\hline Efluente & 8 & 0 \\
\hline Esgoto & 8 & 13 \\
\hline Água & 7 & 15 \\
\hline Sanitário & 7 & 0 \\
\hline Ambiente & 6 & 0 \\
\hline Remoção & 6 & 0 \\
\hline Bacia & 6 & 0 \\
\hline Coleta & 5 & 0 \\
\hline Condições & 5 & 0 \\
\hline Custo & 5 & 0 \\
\hline Esgotamento & 5 & 6 \\
\hline Pública & 5 & 0 \\
\hline Matéria & 4 & 0 \\
\hline Orgânica & 4 & 0 \\
\hline
\end{tabular}




\begin{tabular}{|c|c|c|}
\hline Saneamento & 4 & 0 \\
\hline Qualidade & 4 & 0 \\
\hline Legislação & 4 & 0 \\
\hline Cobertura & 4 & 0 \\
\hline População & 3 & 0 \\
\hline Impacto & 3 & 0 \\
\hline Estação & 3 & 0 \\
\hline Sustentável & 3 & 0 \\
\hline Utilização & 3 & 0 \\
\hline Manutenção & 3 & 0 \\
\hline Aplicação & 3 & 0 \\
\hline Consumo & 3 & 0 \\
\hline Sanitária & 3 & 0 \\
\hline Pluvial & 3 & 0 \\
\hline Reservatório & 3 & 0 \\
\hline Coletora & 3 & 0 \\
\hline Ociosidade & 3 & 0 \\
\hline Saúde & 3 & 0 \\
\hline Investimento & 3 & 0 \\
\hline Desempenho & 2 & 0 \\
\hline
\end{tabular}

Fonte: elaborada pelos autores. 


\section{DISCUSSÕES}

\section{Sistema de Esgotamento Unitário}

Sistema Coletivo Unitário soma as vazões das redes dos esgotos com as águas pluviais em uma mesma tubulação. No Brasil tem sistemas pluviométricos irregulares, onde ocorre diferentes vazões em períodos de anos diferentes. Para conceber um sistema de esgotamento unitário é preciso dimensiona-lo para captar a água da chuva nas suas maiores vazões, e em períodos mais secos o sistema superdimensionado ficará obsoleto, com pouca vazão passando pela tubulação que seria apenas a vazão dos esgotos, elevando o custo em relação a construção do sistema de coleta de água de chuva junto com o esgoto.

Em dias de chuvas mais intensas será necessário utilizar um extravasor, uma vez que é necessário coletar a água excedente de chuva, onde torna-se um risco de refluxo do esgoto sanitário para as residências. E em casos de cheias teria extravasamento de bueiros ou então na própria estrutura domiciliar se ocorrer esse retorno do esgoto, e em grande cheias se tem a ocorrência desses extravasamentos do esgoto coletado, o que pode ocorrer mau cheiro em sistema de boca-de-lobo nas drenagens urbanas. (MEDEIROS, 2020).

\section{Sistema de Esgotamento Separador} Absoluto

Nesse sistema separador absoluto as águas pluviais e água residuária é totalmente separada. São coletadas por tubulações diferentes, são encaminhadas para destinos diferentes. Então é dada essa separação da rede de drenagem com a rede de esgoto, onde proporciona um menor custo em relação às canalizações no qual será utilizado um diâmetro menor para coletar tanto água da chuva quanto água do esgoto.

Com relação a água da drenagem pode-se fazer a disposição dessa água coletada em locais mais próximos de onde ela foi gerada, não precisando afastar totalmente essa água como acontece no sistema de esgotamento sanitário. E uma vez que se tem um menor volume de esgoto chegando na ETE, se tem um menor custo com tratamento associado a essa menor vazão.

Adotando o sistema separador absoluto é necessário se ter controle e adotar fiscalização, monitoramento para que evite o caso de haver ligações clandestinas de esgoto no sistema de drenagem e o de drenagem em sistema de esgotamento sanitário. (MEDEIROS, 2020). 
Idealização de Coleta numa Residência

No sistema de esgotamento sanitário separador absoluto, em relação ao esgoto, ele sai das instalações hidrossanitárias de uma residência, é encaminhada para a caixa de inspeção e dessa caixa de inspeção vai haver uma ligação domiciliar a rede coletora pública de coleta de esgoto.

\section{CONCLUSÕES}

Essa pesquisa tinha como finalidade discutir as medidas que buscam modificar e prevenir problemas relacionados ao abastecimento de água, assim como o manejo de água pluvial, coleta e tratamento de esgoto. Buscando entender como a falta de controle e projeção dessas medidas pode acarretar problemas a população, e prejuízos orçamentários aos municípios.

Traz à tona, que a precariedade dos processos utilizados no Brasil, é o grande ofensor em relação a evolução desse trabalho, causando assim diversos problemas que custam em sua maioria, problemas de saúde a população. Observamos que o esgotamento sanitário a princípio tinha como única função e/ou objetivo evitar enchentes nas zonas urbanas. Com a evolução de tais processos temos a evolução do tratamento da rede de esgoto, uma mudança comportamental em relação
A água pluvial vai ser coletada nos telhados onde pode ser encaminhada, por exemplo, para uma boca-de-lobo e dessa boca-de-lobo a água vai ser encaminhada para uma galeria.

Portanto ocorre uma separação da água da chuva com a água do esgoto em tubulações e em canalizações diferentes. (MEDEIROS, 2020).

aos cuidados com a população e mais cuidado com o deposito dos dejetos.

As melhores estruturas do esgotamento sanitário para evitar problemas ocasionados por enchentes são as que possuem o sistema de esgotamento separador absoluto, em que os tipos de águas vão por tubulações diferentes, mas como no Brasil ainda é usado o Sistema de Saneamento Unitário, a condução do conjunto escoamentos sanitários e das aguas pluviais vão para o mesmo destino, onde normalmente vão diretamente para os canais e rios.

Vale salientar que esse estudo não esgota as possibilidades de investigação, desta forma deixa-se como sugestão para pesquisas futuras: mapear as atribuições de cada processo utilizado e propor uma distribuição mais eficiente à luz dos processos voltados ao esgotamento sanitário. 


\section{REFERÊNCIAS}

SILVA, Eduardo Cabral da; Resíduos Sólidos. Aula do dia 17 de novembro de 2020. Disponível em: < https://us02web.zoom.us/rec/play/0J9f0TV C7xZcLz3e6yFtEzET0cLGTDqnfNjAHn4 O23a4IHKufaeXtTA9kmQpWilfrvmKl6y WG_TN_gY4.z2JPNW_Bh8HF96QC?con tinueMode $=$ true\&_x_zm_rtaid=ECB_OUT 8QmaaapTETjybmA.1605983046113.2e8f 9a48195e580f9a28ed7c38c02ebf\&_x_zm_ rhtaid $=316>$. Acesso em: 21 nov. 2020.

MEDEIROS, Giovana. Saneamento Ambiental, Sistema de Esgotamento Sanitário (Sistema Unitário e Sistema Separador). Disponível em: https://www.youtube.com/watch?v=gjDm GcRMcoA. Acesso em: 21 nov. 2020.

FREITAS, Graziela Pinto de; RIBEIRO, Rosinete Batista dos Santos; SILVA, Kardelan Arteiro da; CAVALCANTE, Ingrid Lélis Ricarte. Sistema de tratamento de efluentes para o campus da Universidade Federal de Campina Grande na cidade de Pombal. Revista Verde de Agroecologia e Desenvolvimento Sustentável. V. 11, No 2, p. 08-12, 2016. Disponível em: $<\underline{\text { Revista Verde de }}$ Agroecologia e Desenvolvimento Sustentável (gvaa.com.br)>. Acesso em: 05 nov. 2020.

MAGNANI, Randal; LIMA, Eduardo da Silva; O impacto da nova estação de tratamento de efluentes de município de Resende-RJ para o fortalecimento do conceito de cidade sustentável. Revista de Direito e Sustentabilidade. Salvador v. 4, n. 1, p. 19 - 38 Jan/Jun. 2018.

CHAVES, Vanessa Silva; SCHNEIDER, Erwin Henrique Meneses; LIMA, Arthur Silva Passos; MENDONÇA. Luciana Coêlho; Desempenho das estações de tratamento do esgoto de Aracaju. Revista DAE. núm. 209 | vol. 66 | janeiro a março de 2018.
SOUZA, Claudinei Fonseca; BASTOS, Reinaldo Gaspar; GOMES, Marcus Paulo de Moraes; PULSCHEN, André Arashiro; Eficiência de estação de tratamento de esgoto doméstico visando reuso agrícola. Revista Ambiente \& Água. vol. 10 n. 3 Taubaté - Jul. / Sep. 2015. Disponível em: $<$ Ambiente e Agua - An Interdisciplinary Journal of Applied Science (ambiagua.net)>. Acesso em: 05 nov. 2020.

DIAS, Fabrício Oliveira; SANTOS, Jémison Mattos dos; JESUS, Sampaio de; Tratamento de esgoto doméstico a partir do sistema leito de raízes: Experiência em uma pequena comunidade rural do semiárido brasileiro. Revista Geopauta. Volume 02, $\mathrm{n}^{\circ} .02,2018$

Setembro/dezembro. Disponível em: < Geopauta (uesb.br)>. Acesso em: 05 nov. 2020.

COLARES, Gustavo Stolzenberg; SILVA, Fagner Pereira da; CELENTE, Gleison de Souza; RADKTE, Julia Fernanda; MACHADO, Ênio Leandro; Sistema integrado de tratamento de efluentes sanitários com reatores anaeróbicos sequenciais em batelada e WETLANDS construídos de fluxos alternados. Rebista Tecno-Lógica. Santa Cruz do Sul, v. 22, n. 1, p. 18-24, jan./jun. 2018. Disponível em: http://online.unisc.br/seer/index.php/tecnol ogica.>. Acesso em: 05 nov. 2020.

MORUZZI, Rodrigo Braga; Estimativa do lançamento de água pluvial no sistema de coleta e transporte de esgoto sanitário por meio de práticas de aproveitamento em residências unifamiliares. Eng Sanit Ambient.| v.21 n.1, jan/mar 2016, 85-94.

BERTOLINO, Murilo; KONDAGESKI, Jonas Heitor; WEINSCHUTZ, Regina; Água de chuva domiciliar no esgoto separador absoluto. Revista DAE. núm. 213, vol. 66, outubro a dezembro de 2018. SOUZA, Gisele Silva de; CECCONELLO, Samanta Tolentino; CENTENO, Luana Nunes; Redes ociosas: um estudo de caso 
sobre a percepção da população do bairro Laranjal quanto à obrigatoriedade da ligação dos ramais prediais à rede pública coletora de esgotos. Revista Thema. 2018, volume 15 . $\mathrm{N}^{\circ} 4$. Disponível em:

<https://doi.org/10.15536/thema.15.2018.1 499-1510.882 >. Acesso em: 05 nov. 2020.

RODRIGUES, Gustavo Paiva Weyne; FARIAS, Guilherme Marques; COSTA, Luís Henrique Magalhães; CASTRO, Marco Aurélio Holanda de; Otimização do traçado de redes coletoras de esgoto sanitário via algoritmo genético. Revista

DAE. São Paulo, v. 68, n 222, pp 164-177,
Ed. Esp. Mar 2020. Disponível em: <https://doi.org/10.36659/dae.2020.024>. Acesso em: 05 de nov. 2020.

ZSCHORNACK, Thiago; OLIVEIRA, Therezinha Maria Novais de; Avaliação do impacto da implantação do sistema de esgotamento sanitário na qualidade da água da Bacia Hidrográfica do Rio Cachoeira, em Joinville, Santa Catarina. Revista DAE. Núm. 212, vol. 66, Edição Especial 2018. Disponível em:

<DOI:10.4322/dae.2018.027>. Acesso em: 05 de nov. 2020. 